\title{
Article
}

\section{'You certainly don't go back to the doctor once you've been told, "I'll never understand women like you."' Seeking candidacy and structural competency in the dynamics of domestic abuse disclosure}

Mackenzie, Mhairi, Gannon, Maria, Stanley, Nicky, Cosgrove, Katie and Feder, Gene

Available at http://clok.uclan.ac.uk/28320/

Mackenzie, Mhairi, Gannon, Maria, Stanley, Nicky ORCID: 0000-0002-76441625, Cosgrove, Katie and Feder, Gene (2019) 'You certainly don't go back to the doctor once you've been told, "I'll never understand women like you."' Seeking candidacy and structural competency in the dynamics of domestic abuse disclosure. Sociology of Health \& IIIness, 41 (6). pp. 1159-1174. ISSN 0141-9889

It is advisable to refer to the publisher's version if you intend to cite from the work. http://dx.doi.org/10.1111/1467-9566.12893

For more information about UCLan's research in this area go to and search for < name of research Group >.

For information about Research generally at UCLan please go to http://www.uclan.ac.uk/research/

All outputs in CLoK are protected by Intellectual Property Rights law, including Copyright law. Copyright, IPR and Moral Rights for the works on this site are retained by the individual authors and/or other copyright owners. Terms and conditions for use of this material are defined in the policies page. 


\section{Sociology of Health \& Illness}

'You certainly don't go back to the doctor once you've been told, "I'll never understand women like you."' Seeking candidacy and structural competency in the dynamics of domestic abuse disclosure.

Mhairi Mackenzie ${ }^{1 *}$, Maria Gannon ${ }^{1}$, Nicky Stanley ${ }^{2}$, Katie Cosgrove ${ }^{3}$, Gene Feder $^{4}$.

1. Urban Studies, School of Social \& Political Sciences, University of Glasgow; * Corresponding author: mhairi.mackenzie@glasgow.ac.uk

2. University of Central Lancashire

3. NHS Health Scotland

4. University of Bristol 


\begin{abstract}
A reticence on the part of women to disclose domestic abuse to family doctors, allied to front-line responses that do not always reflect an understanding of the structure and dynamics of domestic abuse, hampers the provision of professional support. Using data from 20 qualitative interviews with women who have experienced domestic abuse, this paper explores their discourse about interacting with family doctors. It is the first study to explore first-hand accounts of these interactions through Dixon Woods' lens of candidacy. It finds disclosure to be inherently dynamic as a process and expands the candidacy lens by considering the: (1) conflicting candidacies of victims and perpetrators; (2) diversionary disclosure tactics deployed by perpetrators; and, (3) the potential role of GPs in imagining candidacies from a structural perspective. By exploring the dynamics of disclosure through the concept of 'structural competency' it finds that in encounters with women who have experienced abuse GPs ineluctably communicate their views on the legitimacy of women's claims for support; these in turn shape future candidacy and help-seeking. Greater GP awareness of the factors creating and sustaining abuse offers the potential for better care and reduced stigmatisation of abused women.
\end{abstract}

Key Words: Doctor-patient interaction; domestic abuse; candidacy; structural competency; primary care 


\section{Prelude: A Micro-story of Ambiguous Domestic Abuse (DA) Disclosure}

Alison's abuse by her partner started 13 years ago when she was pregnant. She ended the relationship when her daughter was 5 years old; 8 years later Alison remains fearful of her expartner's periodic return: 'I'm still to this day terrified if I see him'. This fear is magnified when he is predicted to be nearby:

'There's still that bit of me that's frightened -if I hear there's going to be a funeral in the village, I can feel myself panicking. Because he always treated a funeral as a day, two days, three days, at the pub. And ... that's when he always came to the house, when he had a drink in him. And wanted to smash the place up ... even now, if I know there's a funeral in the village, my doors are double-locked'.

This fear of danger impacts on her own mental and physical health: 'when I get stressed [my] blood sugars go sky high, me being diabetic'. She also recounts how her ex-partner's violence has affected her daughter: 'She doesn't sleep in her own bed. She's thirteen and she sleeps in beside me. Her daughter's fear is based on actual threats to Alison's life - 'she's frightened to leave me in case he comes and kills me because that's what he's told her he's gonnae do' - and impinges significantly on the child's life, not only requiring her to sleep alongside her mother but to have her mother accompany her to social events. The story provides ample hints of the way in which abuse blights health and lives long after an abusive relationship ends.

During the research interview, designed to explore women's experiences of encounters with family doctors, Alison was asked if she had told her doctor (General Practitioner (GP) in the context of the UK NHS) about her abusive (ex)-partner. She did not know for sure and gave responses during the interview that, at first glance, seem contradictory. She starts by saying 'No, I don't think the GP was aware'. Then, although she doesn't specifically remember discussing the abuse, she intuits that the GP knew because she was once told not to worry if her ex-partner came into surgery when she was attending for an appointment - she, Alison, would be put in a separate room:

'I know l've told Dr Johnson because she mentioned something about him [ex-partner] at the time -if I was going to come in and if he was there then I could ask to go and sit in a different room'.

The question of whether her doctor of thirteen years knew about her abuse and its impact on her health started to concern Alison in the interview. Throughout our discussion she comes back 
repeatedly to the puzzling nature of this uncertainty and the apparent contradictions in her own responses. She knows that her health visitor was aware of her abuse - did this mean that the doctor had been informed? She is unsure (although NHS health care protocols would suggest that this would be true). If her GP has spoken to her obliquely about keeping safe within the practice, did this mean that the GP had talked to her about her health in the context of her circumstances? No, this, she thought, had not occurred: 'I don't even know if she remembers me talking about it. She's never brought it up again'.

Throughout the interview she returns to the fact that she had assumed knowledge on the part of the GP and that police involvement would de facto mean that GPs would be informed: 'I just thought that your GP already knew. I thought as soon as there was police involved, your GP was told'. Sometime later in the interview, she repeats: 'I didn't know that they didn't know'. The disruption of her assumptions relating to GP knowledge leads her to want to challenge her GP: 'I would like to bring [this] up to the doctor and say to them 'look, did you know about this? And if so, how?' By the end of the interview, she reflects on the exchanges that she has had with her GP over the last 13 years and concludes that her GP is not aware of the abuse that continues to overshadow her life and that of her child: 'Thinking about it now though, looking back onto appointments that I've had with my doctor, my doctor doesn't know'.

This is not an explicit account of a woman being poorly served nor of it being told in the manner associated with an 'atrocity' story (see later for further discussion). She was not told that DA was irrelevant to her health; indeed, some recognition of the difficulty in encountering her abuser was thought to have been enacted. It is though, a more ordinary account of how silences concerning abuse operate to undermine an entitlement to be heard and to obscure the ways in which abuse (past or present) acts as a social determinant of mental and physical health. Alison's realisation of this very process pre-occupied her during the interview and her question of "look, did you know about this?', as she sought to make sense of her past GP encounters, is central to the concerns of this paper.

\section{Introduction}

DA is recognised as creating the conditions for poor physical and mental health both whilst the abuse is ongoing and beyond (Feder et al, 2011). For over a decade, national and global policy recommendations have recognised the structured and gendered patterning of abuse and have 
advocated for action at multiple levels (legal, political, economic, social, organisational and practice) (WHO, 2010; Council of Europe, 2011, HM Government, 2016, Scottish Government, 2010).

Responding to the abuse experienced by women requires first that it is recognised. Recently efforts have been made to encourage health care professionals, including family doctors, to take the first step in opening 'safe spaces' for disclosures (Feder et al, 2011). Nonetheless, the process of disclosing continues to be a difficult one, resisted sometimes by women and their doctors (McKie et al, 2002). Previous literature syntheses have signalled Dixon Wood's concept of candidacy (2006) as a frame for understanding how disclosure and recognition of abuse dynamically create a sense of legitimacy for health care (Mackenzie et al., 2013; Mackenzie et al., 2015). In this paper, we take this work further in two original ways that produce insights that have significance for both research and practice: we use candidacy for the first time to focus on primary data concerning the micro-level exchange with GPs from the perspective of women who have experienced abuse; and, we introduce the idea of 'structural competency' to the gender-based violence field as a means of considering how practice might be improved (Metzl and Hansen, 2014). Bringing together these concepts and original empirical data drawn from interviews with women, the paper addresses the question of if, and how, there are ways of better practicing structural competency in recognising and responding to DA within GP encounters.

The paper begins by summarising how the existing DA literature connects to the candidacy concept and sets out what is meant by 'structural competency'. Following a description of methods and epistemological orientation, the paper then uses the candidacy frame to consider articulations of: how and why disclosures are made, encouraged or avoided; the nature of the experiences that women have had in seeking help from their GP including the extent to which they perceive themselves to be the right or wrong kind of 'victim' for legitimate support and, narratives of what good GP responses to disclosure might look like. Second, building on these data, the paper discusses structural competency in the everyday practice of recognising DA.

\section{Candidacy}

In a synthesis of literature concerning inequalities in access to/utilisation of health care, Dixon Wood and colleagues developed the concept of candidacy (2006). This served to explain systematic differences in people's journeys into/through health care by characteristics such as socio-economic status and ethnicity. The concept entails the idea that one's self-identification as a candidate for a particular condition, and as a legitimate recipient for services associated with that condition, are socially and culturally influenced in ways that can reproduce inequalities. Candidacy can be shaped 
at any stage of the journey into/through health services by factors such as ease of access to care, how readily one can state and demonstrate one's condition to health care professionals and by the nature of the response to that candidacy by professionals, which may be constrained by institutional, or policy factors.

There has been some testing of candidacy in the health field, largely using narrative interviews, where it has been found useful in understanding how access to and utilisation of health care is made problematic across vulnerable groups and health conditions. An important critique, however, has been that, as first developed, candidacy does not give due weight to structural factors such as class throughout the candidacy journey (D'Ambruoso et al., 2010; Kovandzic et al 2011).

In a literature synthesis, candidacy has subsequently been tested as a means of understanding how women who have experienced abuse journey through a range of public sector services and how these experiences are shaped by intersections of structural factors such as ethnicity, poverty and gender and their manifestation in role identities (such as, motherhood) (Mackenzie et al, 2012; Mackenzie et al., 2015). This synthesis found the stages of the candidacy journey as described by Dixon Woods and colleagues to be highly salient. Thus the work of Cavanagh (2003) and Humphreys and Thiara (2003a) show how women's capacity to view themselves as abused (to acknowledge candidacy) is thwarted by gendered roles and by specific consequences of abusive behaviour such as low self-esteem. Poverty too emerges as a factor that makes abuse less apparent to women as they live day-to-day (Peterson et al., 2005). The problem of accessing and navigating services was brought to the fore by considering women experiencing abuse: with every miss-step in securing safe disclosure to professionals representing not simply a missed opportunity to obtain timely treatment but an actual risk to life (Hamby, 2013). Further, the process of asserting candidacy (making a disclosure of abuse) is widely discussed in the DA literature again with a focus on how class and ethnicity can exacerbate a reluctance to disclose when women 'fear and face misalignments between themselves and services' (Mackenzie et al., 2015: p.14-15). The literature synthesis, for example, highlights the work of Sokoloff and Dupont (2005) where black women in the US express a reluctance to disclose within a criminal justice system perceived to be racist and likely to impart disproportionately punitive responses on their male partners. The synthesis also found that the DA literature usefully highlighted the ways in which professional adjudication and response to abuse disclosure could fundamentally influence women's experiences of support or otherwise. For example, it is recognised that failure to support women who are not ready or able to leave damages future opportunities to promote safety (Humphreys and Thiara, 2003b) and yet not all practitioners are aware of the material and structural reasons why leaving is not thought possible (Burman and 
Chantler, 2005). The synthesis concluded that whilst candidacy was a rich and useful frame for understanding women's access to and experiences of using services, it needed more explicitly to recognise that for individual women candidacies may be multiple and conflicting - with structural and identity factors pushing and pulling them in relation to making disclosures and decisions about detaching themselves from abusive partners and that how candidacies play out in micro-level encounters with professionals is fundamentally impacted also by structural factors.

It is precisely in these micro spaces where women encounter GPs that we find the ideas of structural competency as espoused by Metzl and Hansen (2014) to offer potential for analysis of the ways that disclosures are made (or not), and perceived to be responded to well (or not) .

\section{Structural Competency: a brief introduction.}

Metzl and Hansen argue that in the US the prevailing model for medical education that aims to 'counter marginalisation' (p.126.) has been to increase the 'cultural competency' of family doctors. This entails providing doctors with the knowledge and skills to recognise and respond to crosscultural 'markers of difference' in the expression of illness as they occur in individual clinical encounters. For example, certain cultural norms and practices might lead to stigma around presentations of mental and sexual health problems or to difficulties in engaging with different forms of treatment.

Metzl and Hansen argue, though, that more is required of medical practitioners if stigma and, more broadly, inequalities in health are to be mitigated; specifically, that cultural competency needs to be redefined 'in structural terms' (p. 127). At present, they argue, 'we train doctors to listen to individualised stories, not to structural ones' (p. 128). Structural competency instead requires: 'the trained ability to discern how a host of issues defined clinically as symptoms, attitudes or diseases ... also represent the downstream implications of a number of upstream decisions about such matters as health care and food delivery systems, zoning laws, urban and rural infrastructures, ... or even about the very definitions of illness and health' (p.128). At least three consequences for practice follow from this. First, clinical and 'cultural' presentations need to be reinterpreted in structural terms (not only in relation to social structures such as class and gender but in their manifestations at a political or institutional level). Second, doctors should be trained to recognise that their own status, position and attitudes are produced through the same structures that create iniquitous outcomes for others. Third, not only the medical gaze but also medical endeavour needs to move beyond the consulting room - decisions at a structural level are ones 'with which medicine must engage politically if it wishes to help its patients clinically' (p.127). 
This depiction is one that brings structure to the fore of micro-level encounters in precisely the way that is advocated by the earlier work on candidacy. Structural competency, as described by Metzl and Hansen, also chimes with other writings relating to the creation and exacerbation of health inequalities which argue that the structures which shape health outcomes and their unequal patterning are enacted not only at the macro level of politics and economics but at an organisational level in relation to resources and at the micro-level of professional-patient encounters (Beckfield and Krieger, 2009; Freese and Lutfey, 2011; Lutfey and Freese, 2005). In all of these explanations, therefore, structure plays out not only upstream but midstream and downstream too. A useful example of how structural arguments differ from cultural ones in the context of domestic abuse and gender based violence is found in Chantler and Gangoli (2011) and more recently in Dustin (2016). They describe how cultural arguments are given weight when considering violence in some communities but not in others. Dustin, for example, identifies that cultural arguments are a means of 'othering' certain groups (in this case, minority ethnic groups) such that media discourses of gender based violence use cultural explanations to 'minoritise' abuse in Asian homes yet use individual level explanations for gender based violence in White communities. In neither case do arguments draw on structures of masculinity or class or ethnicity.

In this paper, we make two original contributions. First, we use candidacy for the first time to generate and understand primary data collected to examine women's disclosures to, and with, GPs in doing so we generate new empirically driven developments of the candidacy concept that are set out in subsequent sections. Second, by attending to structures and intersections in these microspaces, we ask whether women's discourses of disclosure help to identify room within primary care for improved 'structural competency' in providing care for those who have experienced abuse. In exploring candidacy and structural competency as concepts we ask how women's experiences of disclosing their abusive to GPs, fully or in snippets over time, make them feel. Does disclosure and the way it is attended to make women feel that they are being listened to and understood or does the telling of abuse exacerbate feelings of powerlessness and illegitimacy as service users? Do women perceive that their GP understands how domestic abuse operates and structures women's space for action and how such space may be further constrained by structural factors such as poverty? What does their experience mean for their subsequent encounters with GPs?

\section{Methods}

We draw on semi-structured interviews with women who have experienced DA to answer these kinds of questions. These interviews were conducted as part of a larger study (Mackenzie et al., 2016; Mackenzie et al., 2018). Ethics approval for the overall study was obtained from the 
University of Glasgow, College of Social Sciences Research Ethics Committee in 2014 with all research participants providing written consent. Here we describe our sampling strategy, the shape of the interview schedule and our analytical strategy as well as potential limitations of our approach.

\section{Sampling}

Women who had experienced abuse were recruited through two types of organisation: Scottish Women's Aid and its local member bodies; and, ASSIST (a specialist DA advocacy and support service focused on supporting victims of abuse through the criminal justice system). Adverts were placed in ASSIST's newsletter and support workers within local Women's Aid groups acted as gatekeepers to possible participants. A total of 20 women consented to participate and interviews were held either in their own home (in the case of three women recruited through ASSIST) or in venues facilitated by Women's Aid organisations (17 women). The criteria for inclusion were that women identified as being a survivor of domestic abuse and did not currently view themselves to be at risk. In our original grant application we had set a recruitment target of 20 women viewing this as achievable and with strong potential for data saturation. As it turned out, we had to work hard with gatekeepers to achieve this target. Our participants were all white British and ranged from their twenties to late sixties. All interviews were conducted by MG.

\section{The Interview Schedule}

The schedule was designed to elicit women's stories of disclosing or withholding information about their abuse to GPs and of how disclosures, if made, were responded to. It sought women's views of the 'ideal' GP response. Interviews schedules were shared with members of our steering group which included a representatives from ASSIST and Scottish Women's Aid but no substantive changes were made to the content of the schedule. All interviews were transcribed in full and pseudonyms given to all participants, to the GPs of whom they spoke and to any other named individuals.

\section{Analysis}

The dominant approach to the coding and analysis of the interview transcripts was thematic. Data related to journeys into/through health services, and the disclosures made or avoided therein, were coded according to a set of predetermined themes relating to concepts of candidacy (such as identification, articulation and adjudication of abuse). Data were deductively coded to additional themes such as the ideal GP response, and the health and social impacts of DA. Finally, an overarching deductive code of structural competency was used to capture those data relating to instances where women discussed examples of GP response and care that connected to the concept of structural competency (as discussed by Metzl \& Hanson, 2013), or its absence, structural 
incompetency. Coding that emerged inductively included the idea of conflicting candidacies of abuser and abused. Coding and analysis of the transcripts was shared by MM and MG with a sample double-coded independently to establish consistency of approach. The use of codes and themes were discussed iteratively through the process and agreement reached on discrepancies - no substantive disagreements were identified.

Thematic analysis is recognised as an appropriate analytic strategy in qualitative research when the aim is to generate patterns across research participants (Mason, 2018). By dissecting transcripts and restructuring data by researcher-determined or emergent themes, can, however, result in decontextualized snippets that conceal underlying narratives as told by research participants. In the process of discussing and iterating themes we became aware of this potential problem and so began to code inductively for internal patterns such as discrepancies and disjointed narratives about historic events (as exemplified in our telling of a portion of Alison's story). This seemed particularly pertinent since women were encouraged to tell stories about multiple disclosures, including disclosures in the distant and recent past and thus about abused lives over the long term. Together these strategies helped us to see within and across transcripts.

In choosing to focus on women's narratives we are mindful of two potential and inter-linked criticisms that we wish to address briefly but squarely. First, we did not gather doctors' accounts of the same encounters, therefore, only half a story of encounters is possible. Indeed, the study was originally designed to have paired interviews but practical and ethical barriers prevented this. Future research would ideally resolve these difficulties and more ethnographic and observational approaches would assist future research in mapping out opportunities for practicing structural competency. Nonetheless, we contend that attending to the data produced by women, who have been abused and have experienced disclosure encounters with their family doctors, is of conceptual and methodological significance in relation to the concerns of this paper. Second, we are aware of debates within medical sociology relating to the appropriate orientation toward narrative data (as captured by Thomas, 2010). We acknowledge that such narratives are social constructions produced by research participants as they interact with researchers rather than a verbatim report of speech and emotions generated by events in the sometimes distant past. Instead, in our view, they provide an important window into how women reflect on their experiences and, like Thomas (2010), we view such constructed narratives as emerging from material realities. Identity management and other discursive practices patently are at play, as they would have been in an imagined set of GP narratives, but, even so, unless we view such narratives as elaborate fictions or even falsehoods, we can still use them to see glimpses of material circumstances and structural forces at play over time. 
Earlier, in setting out our interest in Alison's story for the purposes of this paper, we introduced the term 'atrocity' story - this is a recognised trope within the medical sociology literature where particular devices (such as quoting professionals who are perceived to have acted inappropriately) serve discursively to bolster the narrator (Baruch, 1981). Although the literature on 'atrocity' stories has since been developed to encompass other types of purpose including the signalling of occupational rites of passage or resolvers of ambiguities over occupational boundaries (Allen, 2001), the 'atrocity' story is indicative of a view that the researcher must be fundamentally sceptical of all narrative data and attend primarily to the participant's performance to the detriment of the content. It seems to us that it is possible to take an orientation that is critically friendly to the data that are gathered through narrative accounts - recognising them as indicative of real structures of power and gender and class yet at the same time also as filtered, repackaged and performed experiences. Like Thomas (again), we attend to both positive and negative tellings of our participants experiences and it is in that spirit that we present our findings.

\section{The Dynamics of Disclosure across the Candidacy Journey}

In this section, we aim to demonstrate how candidacy brings to the fore the way in which disclosure is a fundamentally dynamic and negotiated process. To a degree, this is true of disclosing any health need and is central to Dixon Wood's concept of candidacy. Acknowledging that one has symptoms that warrant treatment, deciding to seek help, knowing what kind of help to seek, putting in place a set of potentially complex arrangements in order to obtain help, then declaring that need to a professional and having that need sensitively responded to is self-evidently a chain of decisions rather than a single one and a chain that may require reinforcing or may be broken by others. But DA is a special case in this regard: not only is it shaming and stigmatising (like some health conditions) but its perpetrators actively conspire (sometimes literally) to keep it hidden, its victims are not always listened to and believed, and often the preferred solution proffered by professionals is one that is risky to women. Here, drawing on data specifically collected to explore candidacy amongst women who have experienced abuse, we explore the construction, negotiation and rejection of candidacy. We begin first by considering how self-identification of being abused and contemplation of its disclosure is influenced by structures of power within personal relationships and within material and social contexts.

Dynamics of Disclosure 1: Resistances in Self-Identifying and Disclosing Abuse. 
The first stage of Dixon Wood's candidacy journey is self-identification of the problem for which help might be sought. This is not straightforward in the case of abuse. Women in our study talked of being blind to signs of abuse. As Karen says: 'when I'm telling my story of what happened to me, I can now see where all the red flags were, what he was actually doing to me at the time, but I didn't see it when I was in it'. Ciara also deploys the metaphor of flags (perhaps indicative of learning the language of service provision) that are hidden until, in retrospect, highly visible: 'you're in that environment without realising the danger you're in ... I can look back now and I could see a million flags that I missed'. The capacity to live in abusive circumstances and not perceive the abuse is explained in the literature through the incremental development of abuse (sometimes) in the midst of otherwise loving relationships or where the performance of gendered roles such as good mothers and wives takes emotional precedence (Cavanagh, 2003); Margaret justifies this 'depressed candidacy' when she talks about how behaviours can be normalised: 'I was seventeen when I met my husband so everything that happened, it was just 'That's marriage, that's life. 'An' then it's when you step back an' you see just what you did go through.' As indicated earlier, though, the perpetration of abuse (and, in particular, coercive control) often entails active destabilisation of mental health - in these cases, symptoms of abuse become read by women as evidence of their own guilt - the causes rather than the consequences of abuse. Resisting women's self-identification of abuse becomes a strategic goal for the perpetrator. Karen pinpoints this: 'it's almost like you're blind. They get in your head and just twist everything ... you totally blame yourself'.

When women do recognise that abuse is happening, perpetrator resistance proceeds in two ways. First it seeks to keep the abuse hidden by downplaying symptoms. Second, where keeping abuse invisible is not entirely viable, the perpetrator can seek to manipulate how its symptoms are presented to the outside world. Thus, a thread running through women's discussions of using primary care was how possibilities of disclosing abuse became diverted into disclosures of mental health problems. Two examples illustrate how abusive partners operate to disrupt the disclosure process. First, Rebecca recounts how she was encouraged to seek psychiatric help by her partner who actively sought to influence her state of mind immediately prior to her speaking to her GP: 'he used to keep provoking me to try and convince me that I was the crazy one of the relationship, I actually contacted my GP and I said, "Could I arrange to have a psychiatric assessment?" So I went in to have an assessment ... he [the partner] actually turned up that day when I was sitting in the waiting room, and I ... didn't see or hear him come in. And, the next thing I know is, I hear his voice right in my ear behind me, which scared me, And I was just like, "What did you do that for?" And he said, "Oh just for dramatic effect." You know, 
so I was shaking and a mess when I got in there [to the consultation].

Jeanette similarly tells of her partner consistently attending consultations and answering questions on her behalf: 'There were times that he actively took me somewhere because of the state that he'd got me in. And, they were just like "Oh. And who's this really helpful friend who's brought you here?"'. She goes on to describe this in relation to a failed suicide attempt:

'I took an overdose ... and he took me to the hospital and sat there, and he did all the talking, and eventually the doctor turned to me and he said "So, why don't you tell me what happened?" And he'd started again with "Oh, she's having a really hard time, she's not coping at work, she's not doing very well with this." And I had an outburst, and screamed "That's not true. This is you, and you're doing this to me." And, I remember him and the doctor, they looked at each other and they shared a look of, kind of (sigh). Like exasperated'. As we pick up later, such strategies are frequently successful in derailing recognition of abuse and, invoking the structural competency frame, could be made more salient to practitioners.

Resistance also comes in the form of women's fear of stigmatisation aligning with Goffman's (1963) idea of spoiled identities. In this case, women do not wish to be judged as having transgressed the expectations of their roles. Some express this as embarrassment; others such as Eleanor explicitly feared the label of victim:

I wouldn't say I had a good or a bad relationship with my GP, but it's just that stigma, I think, of reporting and being a victim ... Like your card's marked'.

This indicates a fear of candidacy as a fixed and defining feature of one's identity. A further significant driver of reticence to disclose is the fear that children will be removed from women (Humphreys and Thiara, 2003b; Peckover, 2003; Petersen et al., 2005). The women in our study had either experienced child protection interventions, had fear of them or, if they did not have children, raised it as a hypothetical barrier to disclosure. For Sarah the calculation was a straightforward one: 'so if you're getting beaten up at home, you don't wantae tell anybody ... you don't want social work coming an' taking your kids'. As suggested in earlier work the role of mother substantially conflicts with that of victim of DA (Mackenzie et al, 2015). Finally, the fear of disclosure is not only of stigmatisation but of further violence. Again this has been discussed widely in the literature making a disclosure and the potential exit route that it sets a woman on is a process that is known to come with risk of serious ill treatment including death. Margaret quietly captures this: I mean, there has been a lot o' things that I've went in and no' told my GP because I thought 'Somebody's sitting 
out in the waiting room.' Candidacy is under constant surveillance and such alertness to danger needs to be properly understood by those from whom women seek help.

Before we move on to consider our findings in relation to the general question of how GP responses play into women's experiences we highlight a specific finding that is pertinent to the question of candidacy - the ways in which different contextual factors and GPs' views of them, create the experience of being a (il)legitimate candidate for support.

\section{Dynamics of Disclosure 2: Being the 'Right' Kind of Victim}

Earlier work has identified how features of a woman's life can make her easier or harder to treat as a legitimate candidate for GP support (Mackenzie et al., 2013; 2015). These include how disclosures of abuse are made, other presenting issues and women's readiness to leave the abusive relationship. In this study, where we explicitly sought to explore candidacy first hand, women were all too aware that how they were treated partly rested on factors often outside their control. This is illustrated by Jeanette who recognises that her route to disclosure and support was made easier by two sets of factors - personal resources that allowed her to understand how general practice operates, and, her life circumstances that allowed her to present DA in the best light:

I'm lucky that I've had so many people that advocate for me, and people who've got knowledge of general practice ... that's made a difference in how ... I've been treated and responded to. And the fact that they've only seen that I've been in one relationship, I'm not coming to them after a second or third position where I've been really vulnerable. So... I think that I've been lucky, 'cause I'm not sure that every single person gets that response, or that if I had a different background, or if they knew of a different background of mine, you know, if I had multiple issues, and multiple, sort of, vulnerabilities, if I had any substance misuse ... '.

Jeanette indicates in this quote that a disclosure of abuse is, in her view, potentially stigmatising if it comes alongside indications that a woman is not making the 'right' choices in her life. Marianne, currently on a methadone programme, attests to the way in which candidacy for support feels blurred when signs of lives lived in difficult circumstances are manifest:

'An' the thing wi' me is I take methadone ... and I don't think doctors listen to me as much because I do take methadone. He [the GP] wasn't very sympathetic. I didn't just suffer from domestic violence and rape. ... But he just assumes I want drugs a' the time. . 
The 'wrong' kind of victim is also the woman who does not/cannot separate from an abusive partner. Consistent with previous literature, some women in our study had direct experience of negative reactions when they revealed that they were still living with an abusive partner Cavanagh, 2003). Karen clearly demonstrates how such a reaction (a fundamental failure to understand the structure of abuse) shuts down candidacy claims, responsibilises the woman and closes potential routes to support:

'You certainly don't go back to the doctor once you've been told "I'll never understand women like you." It's not helpful and ... you blame yourself for everything and that's pretty much somebody else telling you it's your fault. So that was my experience'.

The burden of disclosure then becomes two-fold: to open up to the potential stigma of being abused and to reveal that you have not taken the steps to protect yourself by terminating the relationship. This further stigmatisation has been demonstrated to be blind to the social, emotional and financial constraints on leaving as well as a failure to understand the unpredictable and often fatally dangerous nature of disengaging from a long-term controlling partner (Cole, 2001; Humphreys \& Thiara; 2003a\&b; Burman and Chantler, 2005). This lack of comprehension of the scale of the task of leaving is captured in the following extract from Marianne who plays out her doctor's response to her still remaining with her partner. In this, she admits that she understands why the GP displays a certain resignation to her living circumstances but also feels that this is due to him not fully understanding the work and resources involved in disengagement:

'They'll look at you and think, 'Well you're still with him, so it's your own fucking fault.' ... "Are you still in a relationship wi' Kevin?" I'm like, "Yeah." An' they just sorta look at you, "Well see you next weekend then?" "I don't wanna bad-mouth my doctor in that sense 'cause it's bound tae get a bit like frustrating like, ... "So are you still in a relationship wi' this guy?" "Uh huh." An' they go, "Right," like it's your fault, like "okay, I'm sorry". "Well just leave him." I'll just go home an' leave him tomorrow an' that's it". It's never that easy. An' the amount of phone calls I made because I couldn't get him away from my flat. I got him out the house but I couldn't get him away from my flat. An' the doctor doesn't know the half of what l've went through'.

\section{Dynamics of Disclosure 3. Responses to Disclosure}


Thus far we have considered the ways in which women's disclosures of abuse to GPs can be shaped and controlled by their partners as well as by their fears of the profound consequences of their action and have introduced the idea that women operate with ideas of legitimacy in making disclosures and in interpreting responses to those disclosures. In this section we look in more detail at the kinds of response women receive to their disclosures and what this means to them as well as eliciting their views on what ideal responses would look like.

To start, we pick up the threads of Rebecca and Jeanette's stories of direct partner manipulation of the health care encounter. In Rebecca's case (where her partner has turned up in the surgery in order to frighten her 'for dramatic effect'), she explains to her GP why she is upset but, as she tells it, he chooses not to hear her remembered attempt to put her diagnosis in context: "I said, "This has happened," you know, "he's turned up in here and he's done this and I'm upset." And he didn't really say anything about it at all, you know, he just said, "Oh well, you know, nothing we can do about. Let's get on with the assessment." I did the assessment and he just said, "Oh you're just depressed." I said, "Well, you know, I'm stuck in this situation, I need to get..." you know. "No, here's some tablets." Jeanette's story further underlines the ways in which health care professionals can (unwittingly) collude in women being diagnosed with mental health problems in ways that obscure their abuse. Suicidal, and with an ever-present and 'helpful' partner she describes being taken to a crisis centre where she resisted a diagnosis of mental illness because she recognised it as a strategy of control: 'I remember the doctor saying "Have you heard of borderline personality disorder?" And I was like, "D'you know what, you can fuck off. Because I have, and I know that this is what women get levelled with. This is what I get, and this isn't me. I was just lucky that I had enough of a knowledge at that point, where I was like 'No. I'm not taking that. I'm not taking your lack of knowledge on my medical records.'

Women also wanted to be asked about DA. Directly echoing the women from Peckover's 2003 study, Jeanette says: I remember so many times that I was, like, silently screaming for somebody to just ask $m e^{\prime}$. Making a disclosure; actually finding the words and breaching the empty space of a consultation is something that many women find impossible, or at least, very difficult to initiate (McKie et al, 2002). Paula, as a woman with a coercive partner who was not physically violent, questions how one might start the discussion without help: 'Cause tae look at me, I didnae look as though there was anything wrong ...there's no marks on me, so... You know? An' tae walk in there an' tae turn round an' say "I need help?"' What the literature on DA, in conjunction with that on candidacy, helps us to see is that failure to ask about, and recognise signs of, abuse actively plays into women's constructions of being 
an illegitimate candidate for support. Here Marianne describes her GP's response to being told of her DA entailing repeated rape and her reaction to finding that he was fully aware of that abuse but waiting for her to disclose: 'I think they were just waiting, that's the most horrible thing tae be told, "D'you know something, we've been waiting on this for ages." ... my GP personally was just kinda like, "Oh aboot time!"”.

Women described a range of different kinds of responses from their GPs (with one exception, gender of GP seemed to matter and it is not, of course, surprising that female GPs might be more likely to attend and act more sympathetically to conditions of abuse). Many of these were extremely positive. Rebecca's GP was 'very caring - there was no sort of a rush to get out the door ... she really does take the time to sit and talk to you'. Ciara describes having been in 'a kind of highly distressed state mostly in tears by the time I got to my $G P$ ' but there found that she 'was able to describe the situation to her, the access wasn't made stressful for me'.

Tara, who had had her young baby taken from her because of past drug abuse and recent DA was profoundly appreciative of her male GP (the exception referred to above). He is described as emotionally supportive 'my GP's really the only person that says "You've been brilliant. Proud of you, Tara, you've done great." and practically helpful in recognising organisational structures and in helping her fight to have her child returned to her. She says, 'So he was really angry towards social work. His exact words were "Don't gi' the bastards anything to complain aboot." ... He's written letters to the court to say "This lady's fit to look after her child."

Many women in our study highlighted, however, that their experiences had been mixed depending on which GP they saw. Rebecca, for example, has experienced good support: 'my own GP was female and she was a really nice, really kind, really understanding, nurturing woman' but juxtaposes this with the opposite extreme, 'the male one there was just as bad as my ex ... my heart used to drop every time I rang up and said, "Oh you've got it with him." ... basically, you know, you walk into this doctor's surgery and he'd be sitting, as if to say, "What are you," you know, "what do you want?". I come out feeling worse than when I went in'. Marianne describes ongoing encounters which make her feel a burden to her GP: 'he kinda just yawns upon my appointments now, "Oh is it you Marianne?" That's how bad it is ... I feel he's bored, he's bored of my situation. I think they're all bored of it really ... I felt like I was being a burden tae them so sometimes I just wouldn't go'. This example carries echoes of Groves' 1978 characterisation of 'the hateful patient' where 'insatiable dependency' (p. 883) as perceived by doctors leads to the following types entering professional discourse: 'dependent clingers, 
entitled demanders, manipulative help-rejecters and self-destructive deniers' (p.883). Marianne's doctor does not need to use this language explicitly for her to identify an implicit judgement.

Clues to what women think ideal GP responses should look like are apparent in these positive and negative experiences. Close listening, non-judgemental offers of help and, as we saw from Alison's story earlier, an awareness that, for some women, DA has ramifications that extend well into the future following a disclosure and even after separating physically from one's partner. Much of what women were asking for was apparently simple: for GPs to be 'aware of the red flags'; and, to act humanely in seeking disclosures - as Tara suggests, they should be asking "What's happening at home, is everyone alright?" Further, seeking women's views of needed support would be appreciated Marianne captures the kind of response that she would have found helpful and that would have given balance to the weight of disclosure: 'Is there anything else I can do personally as a GP for you? That would be a brilliant question to be asked ... You went in there and opened up a whole can o' worms to your GP, you'd hope that you would get something back.'

If these ideal responses seem small and potentially insignificant then it tells something about how undervalued women feel at the point of disclosure but also reflect how far away from humane actual responses can be perceived to be. As Karen says: 'And it wasn't until after we were out of the consultation that my mum said "He never even asked you how you were." The damage of this kind of response to women's sense of candidacy is captured further by Karen: 'A person who's undergone domestic abuse, your confidence, your self-esteem, your worth, it's on the floor and you don't know if people are going to believe you because you've been told so many times that nobody will believe you. To go into a doctor and tell him this and then not to be validated, yet again, it's probably compounding a lot of the feelings that you're already going through'.

Two women answered the question of how they would ideally like GPs to respond by alluding to gaps in life circumstances between doctor and patient. In Tara's case, she felt these might be breached by a health care professional prepared to see beyond differences in class, experiences or opportunities, in other words, to display structural competency: 'you're nae different fae what I am. It's just that I've had a wee hiccup along my life. It's just maybe you've had an easier life than what I have. I was sexually abused when I was younger so... my childhood was completely taken away from me. I've been knocked doon, back up, knocked doon, back up, knocked doon, back up'. For Sarah, though, bridging the gulf was unimaginable without third party intervention. She describes the work of a specialist drugs project and its advocacy role in making the candidacy of women with drug 
addiction problems visible to GPs: 'I've got a worker ... an' what they're doing at the moment is they're actually getting GPs in for work experience, so that, like, GPs can work wi' the workers an' they can see us an' they can get tae know that we're just normal people like them.' These examples speak to processes of 'othering' and how these might be challenged.

\section{Concluding Discussion - Dynamic Candidacies and Practicing Structural Competency}

As with earlier work testing candidacy in secondary studies (Mackenzie et al., 2015), our study clearly demonstrates that the candidacy frame resonates strongly with women's discourses of disclosure but also demonstrates new aspects of candidacy - some that may be specific to those experiencing crimes of abuse whilst others may have applicability to disclosures of other health needs.

From self-identification through accessing services, making a disclosure and receiving a response from GPs, women's candidacy as requiring and deserving support is fragile and actively challenged. As identified in the earlier testing of candidacy, disclosures are challenged by self-doubt and low selfesteem, by multiple and conflicting candidacies within a woman's role and by responses from health care professionals. That earlier work has already called for better professional and organisational awareness of how structural factors such as gender, class, and ethnicity shape experiences of abuse.

The current study emphasises other important nuances of candidacy in the context of abuse - each of these constitute the broader picture of how abuse is created, sustained, hidden and ultimately experienced. Each also suggests the knowledge of structure that might better inform the practice of those who work with women who have experienced abuse and the potential spaces within which structural competency might be augmented. We take these new aspects of candidacy in turn.

First, the idea of conflicting candidacy that was introduced by Mackenzie et al (2015) to signify where multiple roles and intersections might conflict in the process of self-identifying abuse needs to be expanded to explicitly recognise the dynamic and conflicting candidacies of victim and perpetrator. It is no surprise that, in relationships characterised by coercive control, selfidentification is itself a site of strife with perpetrator's use of devices that they deploy more generally in pursuit of abuse specifically used to stifle self-identification. Linked to this, as we have shown, is the process of diversionary disclosure where, again, the tools of control, are used not only to foreclose disclosure of abuse but to depress candidacy by securing other stigmatising mental health diagnoses. Being alert to these devices of control and to their links to material and emotional sources of power is fundamental to the competent care of women who are being abused. Likewise, 
empathetic care is rooted in non-stigmatising practices; in the case of domestic abuse it means bridging the gulf that can be represented by the act of disclosure. This again means being alert to processes that keep abuse hidden or distorted (particularly problematic perhaps where doctors find themselves caring for both victim and perpetrator), to tentative attempts at disclosure and avoiding the requirement for women to make double disclosures - as requiring help and being legitimate recipients of help. Finally, and particularly pertinent to the idea of structural competency, the discourses of women in our study suggest the over-arching importance of doctors imagining candidacy. By this we mean that for structural competence to be enacted then GPs need not only to be aware of how a myriad of structural factors shape life circumstances but to analyse and understand individual presentations in those terms - to recognise their own comparative advantages, how these are communicated to women and the ways these may contribute positively or negatively to women's disclosures. In other words, structural competency is not simply a technical fix; instead it requires recognition and empathetic response to 'biases, inequities and blind spots' (Metzl \& Hansen, 2014:p.128).

In the context of modern clinical encounters, time within GP appointments is at a premium but the data presented in this paper are not indicative of the need for unrealistic additional resources. Indeed, the kinds of responses that women wanted (and that some received), as we have already indicated, were both infinitesimally small in scale as interventions but potentially life-changing in effect. The challenge is how they might be brought about (and it is here that more research is required) - to reiterate, as Metzl and Hansen indicate, structural competency is not a set of technical skills to be achieved through attendance at a training course but, instead, might be achieved over a lifetime of practice and education. Its importance though is attested to through the discourses foregrounded in this study - we turn back, finally, to Alison's story with which we opened this paper and ask how, in cases such as this, structural competency might have brought about a different and more positive set of experiences.

There are, we suggest, two fundamental improvements that might have ensued from a more structurally aware perspective of abuse that recognised the dynamics of disclosure as described. One, disclosure would not have been an indistinct, forgotten or avoided event - Alison would not have to ask after 13 years of interaction: 'Look, did you know about this?' Second, and related, health care subsequent to disclosure(s) would have been attuned to ongoing health consequences for Alison and her daughter and to instances of continued abuse beyond the formal termination of the relationships. Taken together, these have the potential to mitigate in a small but fundamental way, a sense of stigma and shame. 


\section{Summary}

This paper has explored the discourses of women who have experienced domestic abuse as they talk about their interactions with GPs. It is the first study to explore first-hand accounts of these interactions through the lens of candidacy. It finds disclosure to be inherently dynamic as a process and expands the candidacy lens in relation to abuse by considering the conflicting candidacies of victims and perpetrators, the diversionary disclosure tactics deployed by perpetrators and the possible role of GPs in imagining candidacies from a structural perspective.

Related to this final point, the paper also explores the dynamics of disclosure through the concept of 'structural competency'. It finds that GP encounters with women who have experienced abuse are ones through which GPs ineluctably communicate their views on the legitimacy of women's claims for support; these in turn can plausibly shape future candidacy and help-seeking. Greater awareness on the part of GPs of the factors creating and sustaining abuse offers the potential for better care and reduced stigmatisation of abused women.

\section{Acknowledgements}

We would like to thank the women who generously gave their time to take part in this study. In addition, we thank the funders (Chief Scientist Office of the Scottish Government, the two anonymous reviewers who helped us to improve the paper and to Annette Hastings, Ade Kearns and Sharon Wright in Urban Studies at the University of Glasgow who read and commented on drafts at various stages.

\section{References}

Allen, D. (2001) ' Narrating Nursing Jurisdictions: 'Atrocity Stories' and Boundary-Work'. Symbolic Interatction, 24(10:75-103

Baruch, G. (1981) 'Moral Tales: parents' stories of encounters with the health professions'. Sociology of Health \& IIIness 3(3):275-295.

Beckfield, J., Krieger, N. (2009) 'Epi + demos + cracy: Linking Political Systems and Priorities to the Magnitude of Health Inequities-Evidence, Gaps, and a Research Agenda'. Epidemiologic Reviews, 31(1):152-177. 
Burman, E. and Chantler, K. (2005) 'Domestic violence and minoritisation: legal and policy barriers facing minoritized women leaving violent relationships', International Journal of Law and Psychiatry, 28(1):59-74.

Council of Europe (2011) Convention on preventing and combating violence against women and domestic violence. https://wcd.coe.int/ViewDoc.jsp?id=1772191

D’Ambruoso, L., Byass, P. and Qomariyah, S. (2010), 'Maybe it was her fate and maybe she ran out of blood': Final Caregivers Perspectives on Access to Care in Obstetric Emergencies in Rural Indonesia, Journal of Biosocial Science, 42:213-41.

Dixon-Woods, M., Kirk, D., Agarwal, S., Annandale, E., Arthur, A., Harvey, J., Hsu, R., Katbamna, S., Olsen, R., Smith, L., Riley, R. and Sutton, A. J. (2006) 'Conducting a critical interpretive synthesis of the literature on access to healthcare by vulnerable groups', BMC Medical Research Methodology, 6,35 .

Dustin, M. (2016) 'Culture or masculinity? Understanding gender-based violence in the UK'. Journal of Poverty and Social Justice 24(1):51-62.

Cavanagh, K. (2003) 'Understanding women's responses to domestic violence', Qualitative Social Work, 2(3):229-49.

Chantler, K. and Gangoli, G. (2011) 'Domestic Violence in Minority Communities': Cultural Norm or Cultural Anomaly?' In R. Thiara, M. Schroettle \& S. Condon (eds) (Ed.), Violence against Women and Ethnicity: Commonalities and Differences across Europe.

Feder, GS, Hutson, M., Ramsay, J., Taket, AR. (2006) Women exposed to intimate partner violence: expectations and experiences when they encounter health care professionals: a meta-analysis of qualitative studies. Arch Intern Med; 166(1): 22-37.

Feder, G., Davies RA, Baird, K. (2011) Identification and Referral to Improve Safety (IRIS) of women experiencing domestic violence with a primary care training and support programme: a cluster randomised controlled trial. Lancet; 378:1788-95.

Freese, J., Lutfey. K. (2011) 'Fundamental Causality: Challenges of an Animating Concept for Medical Sociology' in Pescosolido, B.A., Martin, J.K., McLeod, J., Rogers, A. Handbook of the Sociology of Health, Illness and Healing: A Blueprint for the $21^{\text {st }}$ Century. P: $67-84$. Springer: New York. 
Mackenzie, M., Conway, E., Hastings, A., Munro, M., and O'Donnell, C. A. (2015) Intersections and multiple 'candidacies': exploring connections between two theoretical perspectives on domestic abuse and their implications for practicing policy. Social Policy and Society, 14:1474-7464.

Mackenzie, M., Conway, E., Hastings, A., Munro, M., and O'Donnell, C. (2013) Is 'candidacy' a useful concept for understanding journeys through public services? A critical interpretive literature synthesis. Social Policy and Administration, 47(7):806-825.

Goffman, E. (1963) Stigma: Notes on the Management of Spoiled Identity. Simon \& Schuster: New York.

Groves, J. (1978) 'Taking Care of the Hateful Patient'. New England Journal Medicine, 298:883-887.

Hamby, S. (2013) Battered Women's Protective Strategies, Oxford: Oxford University Press.

HM Government (2016) Ending Violence against Women and Girls Strategy 2016 - 2020. HM Government: London.

Humphreys, C. and Thiara, R. (2003a) 'Mental health and domestic violence: 'I call it symptoms of abuse', British Journal of Social Work, 33(2):209-26.

Humphreys, C. and Thiara, R. (2003b) 'Neither justice nor protection: women's experiences of postseparation violence', Journal of Social Welfare and Family Law, 25(3):195-214.

Kovandzic, M., Chew-Graham, C., Reeve, J., Edwards, E., Peters, S., Edge, D., Aseem, S., Gask, L. and Dowrick, C. (2011) 'Access to primary mental health care for hard-to-reach groups: From 'silent suffering' to 'making it work', Social Science \& Medicine, 72:763-72.

Lutfey, K., Freese, J. (2005) 'Toward Some Fundamentals of Fundamental Causality: Socioeconomic Status and Health in the Routine Clinic Visit for Diabetes' American Journal of Sociology, 110(5): 1326-1372.

Mackenzie, M., Conway, E., Hastings, A., Munro, M., and O'Donnell, C. (2013) Is 'candidacy' a useful concept for understanding journeys through public services? A critical interpretive literature synthesis. Social Policy and Administration, 47 (7): 806-825. 
Mackenzie, M., Conway, E., Hastings, A., Munro, M., and O'Donnell, C. A. (2015) Intersections and multiple 'candidacies': exploring connections between two theoretical perspectives on domestic abuse and their implications for practicing policy. Social Policy and Society, 14: 1474-7464.

Mackenzie, M., Gannon, M., Barton, D., Cosgrove, K., Feder, G., Stanley., N. (2016) Chief Scientist Office Final Report: Police To Primary Care: Police to Primary Care: Testing the feasibility and acceptability of a high risk domestic abuse referral pilot.

Mackenzie, M., Bradley, L., Conway, E., Gannon, M., Barton, D., Cosgrove, K., Feder, G., Stanley, N. (2018) 'Calling Police to Primary Care? Approaching the (non)implementation of a Domestic Abuse Notification Scheme through Normalisation Process Theory'. Social Policy and Administration.

Mason, J. (2018). Qualitative Researching. Sage: London.

McKie, L., Fennell, B., Mildorf, J. (2002) 'Time to disclose, timing disclosure: GPs' discourses on disclosing domestic abuse in primary care', Sociology of Health and Illness, 24(3): 327-346.

Metzl, J., Hansen, M. (2014) Structural competency: Theorizing a new medical engagement with stigma and inequality', Social Science \& Medicine, 103:126-133.

Peckover, S. (2003) "II could have just done with a little more help": an analysis of women's helpseeking from health visitors in the context of domestic violence', Health and Social Care in the Community, 11(3): 275-82.

Petersen, R., Kathryn, E., Moracco, K. E., Goldstein, K. M. and Clark, K. A. (2005) 'Moving beyond disclosure: women's perspectives on barriers and motivators to seeking assistance for intimate partner violence', Women and Health, 40(3): 63-76.

Sokoloff, N. J. and Dupont, I. (2005) 'Domestic violence at the intersections of race, class, and gender', Violence Against Women, 11(1):38-64.

Szilassy, E., Drinkwater, J. Hester, M., Larkins, C. Stanley, N., Turner, W. and Feder, G. (2015) Working Together, Working Apart: General Practice Professionals' Perspectives on Interagency Collaboration in Relation to Children Experiencing Domestic Violence. In Stanley, N. and Humphreys, C. (eds) Domestic Violence and Protecting Children: New Thinking and Approaches. London: Jessica Kingsley. 
The Scottish Government (2014) ‘Equally Safe: Scotland’s strategy for preventing and eradicating violence against women and girls', The Scottish Government: Edinburgh.

Thomas, C. (2010) 'Negotiating the contested terrain of narrative methods in illness contexts'. Sociology of Health \& IIIness 32(4):647-660.

World Health Organization/London School of Hygiene and Tropical Medicine (2010) Preventing intimate partner and sexual violence against women: taking action and generating evidence. Geneva: World Health Organization. 